\title{
QUALIDADE DA EDUCAÇÃO SUPERIOR E DESIGUALDADES: UM PANORAMA DOS TEMAS DE ESTUDO (2007 - 2017)
}

\author{
Julian Silveira Diogo de Ávila Fontoura ${ }^{1}$ \\ Berenice Corsetti ${ }^{2}$
}

\begin{abstract}
RESUMO: A investigação aqui apresentada busca compreender a forma como as temáticas da qualidade da educação e desigualdades, são percebidas frente as pesquisas acadêmicas de Programas brasileiros de Pós-Graduação stricto sensu entre os anos de 2007 e 2017, a partir da identificação dos temas de pesquisa privilegiados por essas comunidades de pesquisa. Na produção dos dados, utilizamos os princípios de Estado de Conhecimento, a partir da pesquisa bibliográfica e seu foco históricobibliográfico, exploratório-investigativo, inventariante e descritivo. Os resultados desta investigação acabam por evidenciar a complexidade presente na articulação dos temas qualidade e desigualdades, além da presença marcada de distintos campos disciplinares para o entendimento dos fenômenos relacionados. A partir das categorias emergentes associadas aos contextos das políticas públicas, aos contextos sociais e aos contextos institucionais, temos um conjunto de temas de pesquisas desenvolvidos no período, em destaque aqueles relacionados a avaliação e garantia da qualidade; e a gestão institucional dos espaços acadêmicos a luz dos contextos institucionais.
\end{abstract}

Palavras-chave: Qualidade da Educação. Desigualdades. Estado do Conhecimento. Produção do Conhecimento. Comunidades de Pesquisa. Educação Superior.

\section{QUALITY OF HIGHER EDUCATION AND INEQUALITIES: A VIEW OF THE STUDY TOPICS (2007 - 2017)}

ABSTRACT: The research presented here seeks to understand how the themes of quality of education and inequalities are perceived in the face of academic research from Brazilian graduate programs stricto sensu between the years 2007 and 2017,

\footnotetext{
${ }^{1}$ Doutor em Educação pela Universidade do Vale do Rio dos Sinos (UNISINOS). Professor da Rede Pública de Ensino do Estado do Rio Grande do Sul (SEDUC/RS - 1a CRE). E-mail: julian.diogo@gmail.com.

${ }^{2}$ Doutora em Educação pela Universidade Estadual de Campinas (UNICAMP). Professora titular da Universidade do Vale do Rio dos Sinos (UNISINOS), integrando o corpo docente permanente do Programa de Pós-Graduação em Educação (PPGEdu)-UNISINOS. Bolsista de Produtividade em Pesquisa 1D CNPq. E-mail: bcosetti@unisinos.br.
} 
from the identification of the privileged research themes these research communities. In the production of data, we use the principles of State of Knowledge, based on bibliographic research and its historical-bibliographic, exploratoryinvestigative, inventive and descriptive focus. The results of this investigation end up showing the complexity present in the articulation of the themes of quality and inequality, in addition to the marked presence of different disciplinary fields for the understanding of related phenomena. From the emerging categories associated with public policy contexts, social contexts and institutional contexts, we have a set of research themes developed in the period, in particular those related to evaluation and quality assurance; and the institutional management of academic spaces in the light of institutional contexts.

Keywords: Quality of Education. Inequalities State of Knowledge. Knowledge Production. Research Communities. Higher Education.

\section{CALIDAD DE LA EDUCACIÓN SUPERIOR Y DESIGUALDADES: UN PANORAMA DE LOS TEMAS DE ESTUDIO (2007 - 2017)}

RESUMEN: La investigación presentada aquí busca comprender cómo se perciben los temas de calidad de la educación y las desigualdades frente a la investigación académica de los programas de posgrado brasileños stricto sensu entre los años 2007 y 2017, a partir de la identificación de los temas de investigación privilegiados. Estas comunidades de investigación. En la producción de datos, utilizamos los principios del estado del conocimiento, basados en la investigación bibliográfica y su enfoque histórico-bibliográfico, exploratorio-investigativo, inventivo y descriptivo. Los resultados de esta investigación terminan mostrando la complejidad presente en la articulación de los temas de calidad y desigualdad, además de la marcada presencia de diferentes campos disciplinarios para la comprensión de los fenómenos relacionados. De las categorías emergentes asociadas con los contextos de políticas públicas, los contextos sociales y los contextos institucionales, tenemos un conjunto de temas de investigación desarrollados en el período, en particular los relacionados con la evaluación y el aseguramiento de la calidad; y la gestión institucional de los espacios académicos a la luz de los contextos institucionales.

Palabras clave: Calidad de la educación. Desigualdades Estado del conocimiento. Producción de conocimiento. Comunidades de investigación. Educación Superior. 


\section{Introdução}

A partir da segunda metade do século XX, a Educação Superior nunca fora tão estudada pela comunidade de pesquisadores como na atualidade, tanto em nível nacional, quanto internacional (DALLA-CORTE; SARTURI, 2015), este movimento de pesquisa vem se consolidando a partir das novas (e constantes) transformações que a Educação Universitária vem sofrendo ao longo do tempo. Podemos destacar como grandes influências neste processo de transformação as recomendações dos organismos internacionais na formação das políticas de Educação Superior (MAUÉS; BASTOS, 2016), a velocidade que se estabelece o avanço tecnológico no que se refere a produção do conhecimento (LIMA; FARIA, TOSCHI, 2014), a crescente demanda emergente na formação profissional qualificada em nível superior alinhada a diversidade de modelos de gestão das unidades universitárias em nível nacional e internacional (OLIVEIRA; MARTINELLI, 2014) no qual as Instituições de Ensino Superior se inserem, especialmente no contexto brasileiro, como aponta Fontoura e Morosini (2017, p. 139).

Nos debates que emergem sobre a Educação Superior, algumas questões transversalizam a discussão, já que a Educação Superior compõem-se como um verdadeiro mosaico (FONTOURA, 2018, p. 24) multifacetado, se constitui a partir de diversas conformações em suas arquiteturas institucionais (CAVALCANTE, 2000, p. 21). Esta "bricolagem" se manifesta - segundo alguns autores - por uma série de componentes, como a perspectivas de justiça e política social (BIANCHETTI, 2001, p. 95), presentes nos processos de acesso e permanência; os mecanismos de implementação de fomento a políticas educacionais (MARTINS, 1993, p. 19), a noção de educação que fundamenta a sua articulação e a sua execução junto ao Sistema Nacional de Educação (ARANHA, 1996, p. 50), e ainda os aspectos sociais de legitimação da sua importância junto a sociedade (RISTOFF, 2014, p. 723).

Entre todos estes aspectos, algumas perspectivas - no entendimento dos fenômenos - emergem na disputa por destaque nas reflexões entre os pesquisadores da área de estudos da educação: investigações alinhadas a Educação Superior na perspectiva da qualidade, em consonância com os processos de avaliação (o papel dos indicadores educacionais, avaliações em larga escala, os diferentes sistemas de 
avaliação, entre outros); e o entendimento da Educação Superior a partir dos diferentes contextos no qual as múltiplas desigualdades se apresentam frente as demandas sociais de educação (democratização do acesso, permanência na Educação Superior, processos de inclusão, ações afirmativas, questões de gênero e raça, etc). Desta forma, refletir sobre os processos no qual a Educação Superior se articula as perspectivas de qualidade da educação e das desigualdades de forma combinada, nos parece imperativo para o debate científico.

Existe uma proximidade entre as dimensões da qualidade da Educação Superior e as desigualdades, a partir de distintas perspectivas de análise, em seus estudos, Sguissardi (2000), nos ajuda neste entendimento, ao perceber a Educação Superior como sendo um desafio para todos os países, tendo assim graus e escalas extremamente variáveis, porém o que a define como prioridade é o estágio e modo de desenvolvimento de cada nação. Assim, o modelo de Educação Superior implementado pelas nações serve para a "formação" de determinados papéis sociais, de acordo com a própria história e avanços socio-democráticos desses países e do seu sistema educacional. Os processos de transformação da Educação Superior, por este viés, podem ser entendidos como um conjunto reformas que objetivam o atendimento das demandas sociais pela democratização da Universidade, pondo fim a uma história de exclusão de grupos sociais (SVARTMAN; CROCHÍK; MASSOLA, 2016).

Dias Sobrinho e Ristoff (2002), apontam que é indispensável para um modelo de educação sustentável que anseie pelo desenvolvimento dos indivíduos e consequentemente da nação, com foco na inclusão social, na redução das disparidades e na promoção de uma maior acessibilidade à formação superior. Educação de qualidade sem democratização da oportunidade equivale a defender oligarquias um elitismo inaceitável, a partir destes breves apontamentos, o estudo aqui apresentado, busca perceber a forma como as comunidades de pesquisa pertencentes aos Programas brasileiros stricto sensu de Pós-Graduação, consubstanciam seus estudos/investigações (teses e dissertações) frente as temáticas articuladas: Qualidade da Educação Superior e Desigualdades, nos últimos 10 (dez) anos, entre 2007 e 2017, a partir da identificação dos temas de pesquisa por eles privilegiados em suas investigações. 
A produção dos dados ocorreu a partir da utilização dos princípios de Estado do Conhecimento (MOROSINI, 2015), o levantamento do material bibliográfico (teses e dissertações) deu-se junto a base de dados da Biblioteca Digital Brasileira de Teses e Dissertações do Instituto Brasileiro de Informação em Ciência e Tecnologia (BDTD/IBICT). Elencamos a Biblioteca Digital Brasileira de Teses e Dissertações do Instituto Brasileiro de Informação em Ciência e Tecnologia (BDTD/IBICT), tendo em vista seu reconhecimento internacional como um importante repositório de materiais acadêmicos de tecnologia Open Archives Initiative (OAI), integrando os sistemas de informação dos diferentes Programas de Pós-Graduação brasileiros avaliados pela Coordenação de Aperfeiçoamento de Pessoal de Nível Superior (CAPES) e disponibilizando dessa forma, um catálogo nacional de teses e dissertações a partir dos respectivos metadados disponibilizados pelas Instituições de Ensino Superior (IES).

Acreditamos que o estudo aqui apresentado nesse artigo seja um primeiro movimento no sentido de sistematizar o conhecimento produzido sobre as temáticas articuladas Qualidade da Educação Superior e Desigualdades, de forma a evidenciar os temas de pesquisa privilegiados, desvelando os principais focos de análise e a forma como as temáticas se apresentam na perspectiva dos Programas de Pós-Graduação brasileiros. Este movimento investigativo, traz um panorama geral da forma como a produção do conhecimento, por parte das comunidades de pesquisa, percebem os fenômenos da Qualidade da Educação Superior e das Desigualdades, no contexto da educação brasileira. Importante ressaltarmos que a discussão conceitual sobre a polissemia presente nos termos qualidade e desigualdades, não são objetos deste estudo, as distintas formas de interpretação desses conceitos, estão presentes no interior de cada item do corpus de análise.

No cenário da educação brasileira, entendemos que seja fundamental compreendermos os processos de produção de conhecimento de temas tão sensíveis ao nosso país, especialmente aqueles ligados a potência da educação como elemento de transformação social, atrelado a mudanças significativas da sociedade. Compreender a dinâmica da produção do conhecimento junto as temáticas articuladas da Qualidade da Educação Superior e Desigualdades acaba por possibilitar um entendimento sobre esses fenômenos sociais refletidos no interior dos espaços acadêmicos, em distintos contextos e dimensões conceituais e teóricas, culminando 
em uma "leitura" do contexto social, a partir das experiencias acadêmicas dos grupos de pesquisa no debate e na discussão do tema.

\section{O caminho metodológico: estratégias de pesquisa}

Da mesma forma que Minayo (2000, p. 16), compreendemos a metodologia como sendo "o caminho do pensamento e a prática exercida na abordagem da realidade", e no estudo aqui apresentado, esta trajetória ganha lugar de destaque pois acaba por assumir um papel indicativo/direcional, já que a sua escolha relaciona-se diretamente com os resultados esperados do estudo, nesse contexto, a metodologia surge também como uma forma de validar a trajetória do processo investigativo no qual se insere a pesquisa (FONTOURA, 2018). A partir da produção bibliográfica (teses e dissertações) de Programas de Pós-Graduação stricto sensu brasileiros, buscamos identificar os temas de investigação privilegiados por essas comunidades de pesquisa em investigações que tragam de forma articulada as temáticas da qualidade da educação superior e desigualdades. Acreditamos que utilizar a estratégia de produção de Estados de Conhecimento, descritos por Morosini (2015), seja uma alternativa interessante para o desenvolvimento deste trabalho, como uma metapesquisa, ou seja, pesquisas sobre as pesquisas.

A utilização de princípios de Estados do Conhecimento pode ser entendida como sendo o mecanismo pelo qual seja possível sistematizar o conhecimento já produzido sobre determinado tema de estudo, já que parte da "identificação, registro, categorização que levem à reflexão e síntese sobre a produção científica de uma determinada área, em um determinado espaço de tempo", como apontam Morosini e Fernandes (2014, p. 154). Assim, os Estados do Conhecimento se aproximam da pesquisa bibliográfica, não deixando de lado em sua construção o foco com a pesquisa de caráter histórico-bibliográfico (FIORENTINI; LORENZATO, 2007), pois além de situar em um momento especifico da elaboração da produção acadêmica, utiliza-se de um material já elaborado (teses, dissertações, artigos, livros, etc); com abordagem exploratória-investigativa (MELO, 2006), no sentido da captação do material que comporá o corpus de análise, incluindo aqui a escolha desse material e a base o mesmo se aloca, de forma não aleatória; inventariante e descritivo (FERREIRA, 2002), pois 
assume o papel de catalogação do material bibliográfico, situado em um tempo, um momento e um espaço específico na produção acadêmica.

A utilização desta metodologia de trabalho, mergulha diretamente da fonte da pesquisa bibliográfica, já que a escrita é a principal forma de divulgação e socialização de saberes e conhecimentos da pesquisa acadêmica, em seus mais diversos suportes (livros, revistas, anais de evento, entre outros). Esta construção toma para si o desafio de trazer para a reflexão da comunidade científica o que está sendo produzido dentro do campo acadêmico sobre determinado tema, almejando ainda mapear esta produção e, nas palavras de Ferreira (2002, p. 258), "tentando responder que aspectos e dimensões vêm sendo destacados e privilegiados em diferentes épocas e lugares". A literatura acaba apontando uma série de perspectivas na produção de Estados de Conhecimento, no que tange a sua operacionalização, optamos - nessa investigação utilizar a visão proposta por Morosini (2015). Os Estados de Conhecimento se efetivam a partir de um percurso metodológico baseado na elaboração de 3 (três) bibliografias (momentos), permitindo assim ao pesquisador uma imersão junto ao material a ser analisado: a Bibliografia Anotada, a Bibliografia Sistematizada e a Bibliografia Categorizada.

Cada uma dessa bibliografias, descritas por Morosini (2015), são diferentes momentos de imersão junto ao corpus de análise, e essa imersão - em seu conjunto acaba por provocar, uma compreensão do material bibliográfico que o pesquisador manipula, fazendo com que as análises subsequentes do material, ocorram de forma ainda mais potente. A Bibliografia Anotada é o momento em que nos aproximamos do material bibliográfico a ser analisado, aqui as escolhas metodológicas começam a ser realizadas: a escolha da base de dados consultada; o período de buscas (no caso aqui apresentado: 2007 a 2017); os descritores, ou metadados de pesquisa que desencadearão a busca junto as bases de dados; e a captação propriamente dita do material bibliográfico que comporá o corpus de análise. Já a Bibliografia Sistematizada, é o momento no qual o material bibliográfico captado, recebe um novo tratamento, passando por um processo de verificação mais denso.

Nessa etapa, outros elementos presentes nas produções bibliográficas que compõem o corpus de análise são identificados, como por exemplo, os temas 
privilegiados pelas teses e dissertações, suas instituições de origem, perspectivas teóricas e metodológicas entre outros ${ }^{3}$.

Por fim, a Bibliografia Categorizada, é o momento da concretização da organização dos dados captados e componentes do corpus de análise, os achados de pesquisa, aqui são reorganizados em unidades de sentido que culminarão nas categorias de análise do estudo, a partir do próprio material empírico. Nos Estados de Conhecimento, esta etapa é fundamental, pois os dados do levantamento, serão expressos através de categorias que nos auxiliem na interpretação dos dados da pesquisa. As categorias podem surgir de forma "espontânea", onde ao observar o conjunto de dados, indicam possíveis ligações/aglomerados (categorias a posteriori), ou ainda, podem ser utilizadas categorias analíticas já conhecidas dentro do campo de estudos (categorias a priori).

A escolha entre categorias a posteriori e a priori são prerrogativas do pesquisador, acreditamos que a sua escolha está ligada a natureza do estudo e aos objetivos do pesquisador na realização da investigação, além da sua experiência prévia no próprio campo de estudos. No estudo aqui apresentado, nos utilizamos de categorias a posteriori na busca pelas possibilidades de novos entendimentos sobre as temáticas articuladas de qualidade da educação superior e desigualdades.

\section{A "Qualidade da Educação Superior" e "Desigualdades" à luz da produção acadêmica recente}

A partir do processo metodológico de utilização de princípios do Estado do Conhecimento (MOROSINI, 2015), no que se refere a captação das produções bibliográficas disponibilizadas pela Biblioteca Digital Brasileira de Teses e Dissertações do Instituto Brasileiro de Informação em Ciência e Tecnologia, alguns apontamentos podem ser realizados. Após o cruzamento dos metadados, na busca avançada, foram localizadas ao todo 217 (duzentos e dezessete) teses e dissertações, ao refinarmos nosso olhar a fim de delimitar ainda mais a captação deste material que posteriormente formara o corpus de análise, selecionamos 52 (cinquenta e dois)

\footnotetext{
3 Esses elementos de aprofundamento estão intimamente ligados aos objetivos do estudo por parte do pesquisador, pois nessa etapa metodológica que são captados os elementos fundamentais para o alcance aos objetivos de pesquisa.
} 
estudos (Tabela 01). Esta seleção do material ocorreu com auxílio da leitura dos resumos, das palavras-chaves e os objetivos gerais e específicos dos estudos apurados.

\begin{tabular}{|c|c|c|c|c|}
\hline $\begin{array}{c}\text { Base de } \\
\text { Dados } \\
\text { Consultada }\end{array}$ & Metadados Utilizados & $\begin{array}{l}\text { Parâmetros De } \\
\text { Busca }\end{array}$ & $\begin{array}{l}\text { Trabalhos } \\
\text { Encontrados }\end{array}$ & $\begin{array}{l}\text { Trabalhos } \\
\text { Selecionados }\end{array}$ \\
\hline \multirow{3}{*}{ BDTD/IBICT } & $\begin{array}{c}\text { Qualidade da Educação Superior } \\
\text { + Desigualdades }\end{array}$ & \multirow{3}{*}{$\begin{array}{c}\text { Busca Avançada: } \\
\text { Assunto + Todos } \\
\text { os Campos }\end{array}$} & 93 & 19 \\
\hline & $\begin{array}{l}\text { Desigualdades + Educação } \\
\text { Superior }\end{array}$ & & 71 & 22 \\
\hline & $\begin{array}{c}\text { Educação Superior + Qualidade } \\
\text { + Desigualdades }\end{array}$ & & 53 & 11 \\
\hline \multicolumn{3}{|c|}{ Total de trabalhos } & 217 & 52 \\
\hline
\end{tabular}

Fonte: Elaborada pelos autores.

Gráfico 01 - Distribuição da produção acadêmica (teses e dissertações) nos últimos 10 anos (2007 a 2017) em relação ao nível desta produção acadêmica, e ao ano de produção.

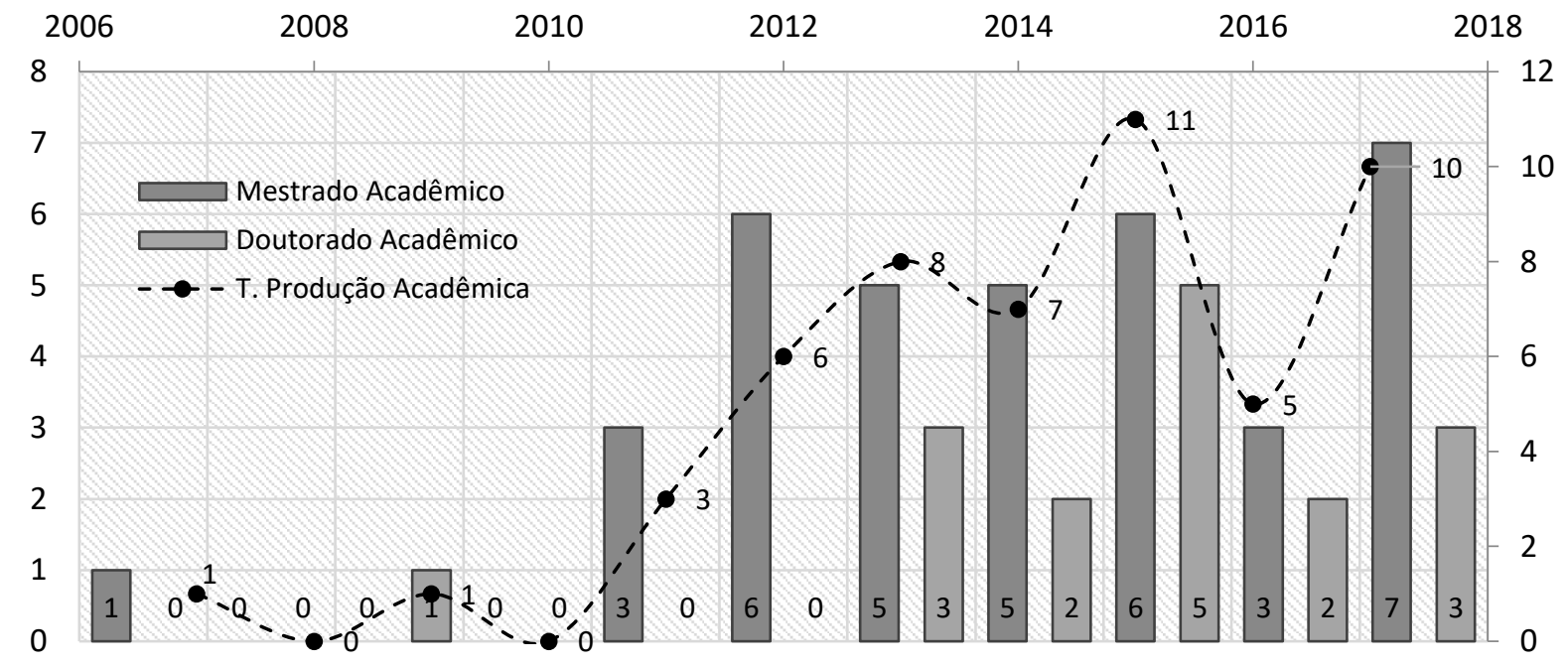

Fonte: Elaborado pelos autores. 
Ao todo, dos 217 (duzentos e dezessete) trabalhos localizados, formam utilizados, cerca de $24 \%$ deste todo, desta forma constituindo o corpus de análise com este montante de teses e dissertações. De forma a complementar os dados apresentados no Tabela 01, expomos no Gráfico 01, a distribuição destes estudos durante o período de 2007 e 2017 a partir do quantitativo destas produções em nível de Pós-Graduação, Mestrado Acadêmico e Doutorado Acadêmico.

Acreditamos que seja importante vislumbramos esse quantitativo, no sentido de dar copo ao corpus de análise, esse quantitativo se mostra como o primeiro movimento de aproximação ao estudo das temáticas da qualidade da educação superior e das desigualdades, posteriormente (Gráfico 01), os desdobramentos desse quantitativo nos auxiliará a compreender a trajetória da produção do conhecimento científico que apresente de forma conjunta a temática no período de 10 anos (2007 2017).

Tendo como base os dados apresentados no Tabela 01, e com ajuda da Bibliografia Sistematizada, percebemos como o tema da Qualidade da Educação Superior e das Desigualdades se materializa junto à comunidade de pesquisadores brasileiros a partir de distintos momentos. No início do período analisado, a produção acadêmica das temáticas articuladas se mostra bastante incipiente (2007 - 1 dissertação; em 2008 nenhuma produção acadêmica; 2009 com a produção de uma tese; e em 2010 sem produções acadêmicas); a partir de 2011 os trabalhos começam a emergir no cenário das produções acadêmicas (com 3 dissertações); em 2012 - de forma crescente - 6 investigações de mestrado; em 2013, seguindo a tendência, temos 8 estudos (destes 5 dissertações e 3 teses); em 2014, um leve declínio (7 estudos, sendo 5 dissertações e 2 teses); 2015 foram produzidos (11 investigações, 6 dissertações e 5 teses), neste período, temos a maior concentração de teses produzidas sobre o tema. Já em 2016, temos o registro de uma queda considerável nas investigações dos Programas de Pós-Graduação, com 5 estudos (3 dissertações, 3 dissertações e 2 teses); e por fim, no último ano, 2017, o conjunto de investigações se compõem a luz de 10 trabalhos (7 dissertações e 3 teses).

Os dados expostos evidenciam o quanto a articulação das temáticas Qualidade da Educação Superior e Desigualdades. O período no qual nos debruçamos, sofreu uma série de oscilações quanto a sua produção acadêmica: nos primeiros anos, os estudos 
se apresentavam de forma bastante primária, e seu quantitativo bastante baixo, apenas em 2011, que esta produção se mostra em um crescente, particularmente nos estudos provenientes dos mestrados (dissertações), as produções de tese se consubstanciam a partir de 2013. É percebido da mesma maneira, as produções no formato de dissertações sobressaem-se sobre os produtos de doutorado (teses).

A Bibliografia Sistematizada nos auxiliou a identificar a origem dos estudos pertencentes ao corpus de análise, a partir da identificação dos Programas de PósGraduação brasileiros que buscam compreender os fenômenos no qual a Qualidade da Educação Superior e as Desigualdades são privilegiados junto ao conjunto bibliográfico (Tabela 02). Acreditamos que esse seja um elemento importante na investigação, pois identificando os distintos campos do conhecimento, podemos perceber ao menos os paradigmas pelo qual as temáticas articuladas emergem. Diferentes áreas do conhecimento acabam por desenvolver investigações sobre os temas articulados, sob diferentes perspectivas características próprias de cada campo do saber.

Tabela 02 - Lista de Programas de Pós-Graduação Brasileiros que compõem o corpus bibliográfico analisado.

\begin{tabular}{lcc}
\hline Programa de Pós-Graduação & N & \% ${ }^{\text {APR }}$ \\
\hline Programa de Pós-Graduação em Educação & 14 & 26,9 \\
Programa de Pós-Graduação em Ciências Sociais & 7 & 13,5 \\
Programa de Pós-Graduação em Políticas Públicas & 6 & 11,5 \\
Programa de Pós-Graduação em Serviço Social & 3 & 5,8 \\
Programa de Pós-Graduação em Direito & 5 & 9,6 \\
Programa de Pós-Graduação em Psicologia Social & 4 & 7,7 \\
Programa de Pós-Graduação em Administração & 2 & 3,8 \\
Programa de Pós-Graduação em Sociologia & 5 & 9,6 \\
Programa de Pós-Graduação em História Social & 3 & 5,8 \\
Programa de Pós-Graduação em Ciências Políticas & 2 & 3,8 \\
Programa de Pós-Graduação em Comunicação & 1 & 1,9 \\
\hline Total & 52 & 100 \\
\hline
\end{tabular}

Fonte: Elaborada pelos autores. 
Dentro do escopo do estudo aqui apresentado, não vamos nos ater a identificar as perspectivas presentes em cada um dos campos do saber e sua influência na produção acadêmica sobre as temáticas articuladas da pesquisa, de qualquer forma, é preciso que fique claro que dentro de cada campo do saber, há uma série de paradigmas estruturais que norteiam as investigações desenvolvidas no campo, semelhante as diferentes formas que perceber os fenômenos sociais a nossa volta.

As temáticas articuladas Qualidade da Educação Superior e Desigualdades, no período entre 2007 e 2017, foram investigadas a partir de diferentes perspectivas, como mostra a Tabela 02, destacamos os Programas de Pós-Graduação em Educação (com pouco mais de um quarto de toda a produção do período), os Programas de PósGraduação em Ciências Sociais (13,5 \% da produção acadêmica levantada do período), e Programas de Pós-Graduação em Políticas Públicas (11,5 \% dos trabalhos produzidos no período). Não podemos deixar de mencionar os Programas de Pós-Graduação em Direito e Pós-Graduação em Sociologia (9,6\% respectivamente), os Programas de PósGraduação em Psicologia Social (7,7\%), os Programas de Pós-Graduação em História Social e Pós-Graduação em Serviço Social (5,8\% cada um), os Programas de PósGraduação em Ciências Políticas (3,8\%), e por fim o Programa de Pós-Graduação em Comunicação (1,9\%) (Gráfico 02).

Gráfico 02 - Distribuição dos distintos campos do saber produtores das pesquisas pertencentes ao corpus de análise (teses e dissertações) em relação ao Programa de Pós-Graduação que foram desenvolvidas as investigações.

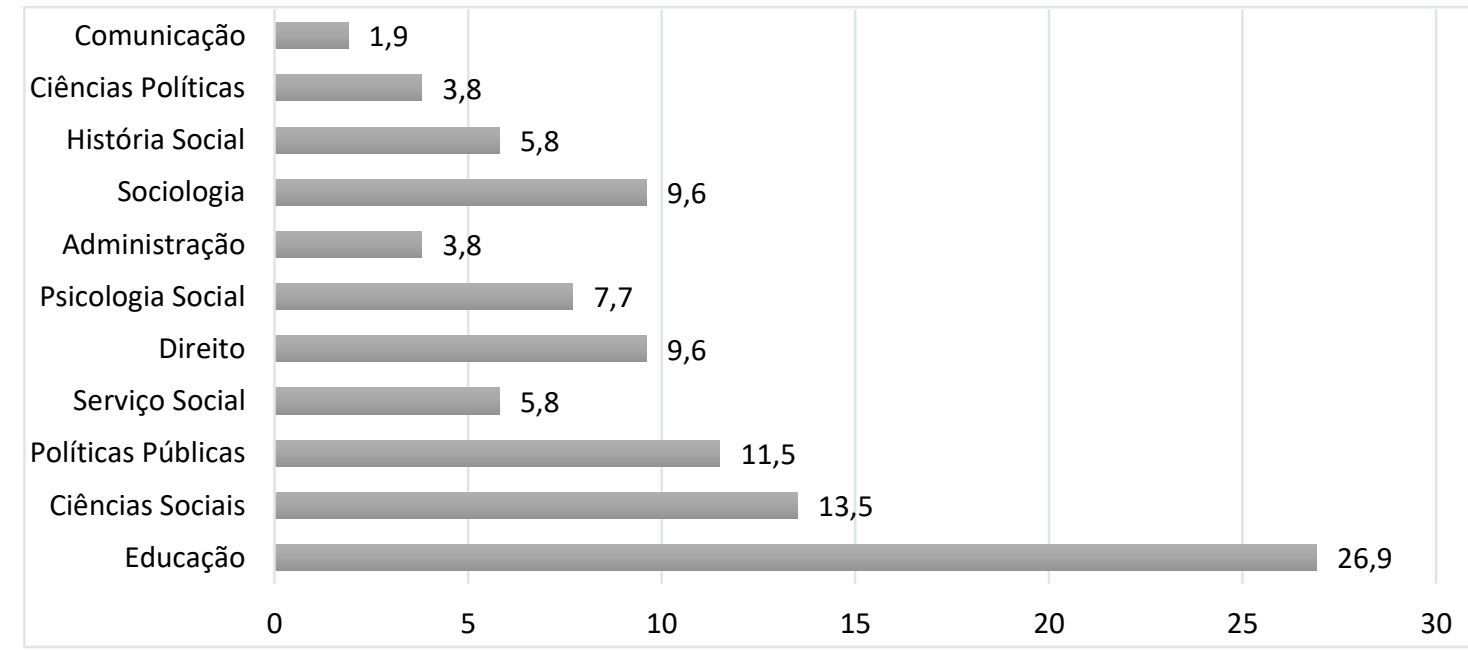

Fonte: Elaborado pelos autores. 
Os dados aqui presentes acabam por demonstrar, em alguma medida, o interesse de distintas comunidades de pesquisa na investigação do tema da qualidade da educação superior, articulada com as desigualdades. Retomamos aqui a ideia de não nos apropriarmos das percepções dos autores sobre os conceitos presentes em seus estudos, esse aspecto acaba fugindo ao escopo da investigação aqui apresentada, de toda forma, a polissemia presente nos termos, acaba por evocar intuitivamente seus sentidos em sua interpretação.

Quando iniciamos o processo de identificação dos temas privilegiados pelos estudos que compõem o banco de dados que construímos, a partir da Bibliografia Sistematizada, percebemos que a composição do corpus se constitui de forma bastante heterogênea. Neste complexo que apresentamos, as comunidades de pesquisa (Programas de Pós-Graduação) se debruçaram sobre alguns temas em particular. Como forma de exposição desses dados, utilizamos a Bibliografia Categorizada, organizamos esses temas de pesquisa identificados no corpus de análise e os organizamos em grandes categorias: Qualidade da Educação Superior e Desigualdades no Contexto das Políticas Públicas, a Qualidade da Educação Superior e Desigualdades em Contextos Sociais e a Qualidade da Educação Superior e Desigualdades em Contextos Institucionais (Tabela 03).

Tabela 03 - Categorias e subcategorias analíticas emergentes do levantamento bibliográfico.

\begin{tabular}{|c|c|c|c|}
\hline Categorias & Temas & $N$ & $\%^{A P R}$ \\
\hline \multirow{3}{*}{$\begin{array}{l}\text { Qualidade da Educação Superior e } \\
\text { Desigualdades no Contexto das } \\
\text { Políticas Públicas }\end{array}$} & Programas, Planos e Ações & 5 & 9,62 \\
\hline & $\begin{array}{l}\text { Acesso/Permanência no Ensino } \\
\text { Superior }\end{array}$ & 6 & 11,54 \\
\hline & SUBTOTAL & 14 & 26,92 \\
\hline \multirow{3}{*}{$\begin{array}{l}\text { Qualidade da Educação Superior e } \\
\text { Desigualdades em Contextos Sociais }\end{array}$} & Indicadores de Qualidade Globais & 4 & 7,69 \\
\hline & Atores Sociais & 3 & 5,77 \\
\hline & SUBTOTAL & 7 & 13,46 \\
\hline $\begin{array}{l}\text { Qualidade da Educação Superior e } \\
\text { Desigualdades em Contextos }\end{array}$ & Avaliação e Garantia de Qualidade & 14 & 26,92 \\
\hline \multirow[t]{2}{*}{ Institucionais } & Gestão Institucional & 17 & 32,69 \\
\hline & SUBTOTAL & 31 & 59,62 \\
\hline Total & & 52 & 100 \\
\hline
\end{tabular}

Fonte: Elaborada pelos autores. 
Na categoria Qualidade da Educação Superior e Desigualdades no Contexto das Políticas Públicas (26,92\%), temos reunidos uma série de estudos (14) que trazem a para reflexão um conjunto de questões relacionadas ao fomento de políticas públicas para a Educação Superior considerando os diferentes espaços, contextos e cenários de educação, destacamos a "cartografia da pobreza" brasileira que aparece de forma bastante expressiva nos estudos e a importância da formação de quadros qualificados para o desenvolvimento efetivo dessas regiões. Aqui temos 2 (dois) temas relacionadas a esta realidade: Há um grupo de investigações que se debruça na compreensão da formulação de Programas, Planos e Ações de promoção da qualidade da Educação Superior em um contexto de vulnerabilidade (9,62\%); e outra perspectiva analítica que acaba ilustrando um importante debate dentro dos estudos sobre a Educação Superior no contexto brasileiro, Acesso/Permanência no Ensino Superior (11,54\%), que buscam ilustrar os movimentos da políticas na promoção de uma educação de qualidade que estruturalmente disponha de recursos que garantam o acesso ao alunado da Educação Superior, e posteriormente ações institucionais que o auxiliem a permanecer na instituição e ensino.

Junto a categoria Qualidade da Educação Superior e Desigualdades em Contextos Sociais $(13,46 \%)$, aqui termos reunidas investigações, que percebem os fenômenos articulados da qualidade da educação superior e desigualdades, a luz de agentes exógenos as práticas de ensino desenvolvidas no interior das Instituições de Ensino Superior, a partir das questões que atravessam o cotidiano do alunado, como a empregabilidade, a sensação de pertencimento, o estímulo familiar entre outros. Dessa forma, 2 (dois) temas aparecem no conjunto dos dados analisados: os Indicadores de Qualidade Globais (7,69\%) que buscam trazer para a reflexão das comunidades de pesquisa o impacto de dimensões como segurança, saúde, moradia entre outras dimensões no sucesso do alunado, relacionando-as com os indicadores de qualidade social, evidenciando a sua importância junto ao trânsito formativo dos sujeitos; por outro lado, temos como outro tema de estudo nesse conjunto, um foco nos Atores Sociais $(5,77 \%)$ a partir do entendimento da formação alunado (moral, intelectual, cidadã) como o foco da Universidade contemporânea, aqui estão presentes investigações que focalizam seus esforços na relação estabelecida entre universidade 
e sujeito, indicando ainda elementos de fortalecimento e enfraquecimento dessa relação repleta de tensões naturais do campo social.

E por fim, temos a categoria Qualidade da Educação Superior e Desigualdades em Contextos Institucionais (59,62\%) abarcando investigações que trazem a qualidade e as desigualdades no cenário das instituições de Ensino Superior a partir da preocupação dos processos, práticas e ferramentas que são implementadas e ou desenvolvidas e articuladas no interior destas instituições. Assim surgem como temas a Gestão Institucional (32,69\%) e suas estratégias para o alcance dos objetivos educacionais, a partir da preocupação das comunidades de pesquisa no que se refere a (re)significação das práticas de gestão na promoção da qualidade da educação e ao mesmo tempo no combate a desigualdade estrutural presente no sistema de Educação Superior; e de forma associada, emerge o tema da Avaliação e Garantia de Qualidade da Educação (26,92\%) como um elemento de aferição dos processos desenvolvidos no interior das instituições de ensino, a luz do retorno do planejamento e do investimento feito por essas instituições para garantir a qualidade da educação ofertada, sobre diferentes vieses. As noções de eficiência e eficácia aparecem de forma bastante significativa no conjunto destas investigações, especialmente se levarmos o paradigma que estes estudos se apresentam (racionalidade científica), importante destacarmos que no conjunto de estudos, poucos mostram a importância do acompanhamento das avaliações como recurso dialógico na consolidação do processo de aprendizagem.

Com os dados produzidos e expostos na Tabela 03, temos um panorama da forma como as temáticas da Qualidade da Educação Superior e Desigualdades são construídas pelas distintas comunidades de pesquisadores brasileiros, de diferentes Programas de Pós-Graduação (Tabela 02), nos diferentes níveis (Gráfico 01) de formação acadêmica de jovens pesquisadores. A maior parte dos estudos que compõem o corpus de análise, acabam se debruçando sobre Qualidade da Educação Superior e Desigualdades em Contextos Institucionais, em especial na dimensão da Gestão das Instituições de Ensino Superior. Isto acaba por indicar de certa forma, uma tendência junto as produções de conhecimento sobre as temáticas articuladas na compressão de fatores endógenos (internos) aos processos de aprendizagem, que aparecem em segundo plano. A compreensão da institucionalidade presente na Educação Superior, a partir da Gestão evoca a necessidade de repensarmos o espaço 
universitário como um elemento de participação coletiva onde os diferentes sujeitos experienciam de forma efetiva processos inclusivos que incorporem em seu cerne um conjunto de práticas que potencializem a qualidade da educação ofertada para os sujeitos do espaço acadêmico.

\section{Algumas considerações}

Este estudo se apresenta como sendo um primeiro movimento de aproximação com as temáticas da Qualidade da Educação e Desigualdades de forma articulada, no sentido de perceber as relações que as diferentes comunidades de pesquisa brasileiras se apropriam destes temas em seus estudos no âmbito da Pós-Graduação (mestrado e doutorado). A utilização dos princípios de Estado do Conhecimento, possibilitou o levantamento do material bibliográfico, relativo as temáticas de pesquisa investigadas, se mostrando ainda uma interessante estratégia não apenas na captação de material, mas sim como um mecanismo de compreensão e manuseio desse material, já que opera em diferentes dimensões, tanto teóricas, quanto instrumentais na investigação de diferentes temas. Entendemos que as temáticas da qualidade da educação e das desigualdades, por si só são extremamente complexas, e quando as percebemos juntas, essa complexidade se apresente de forma bastante intensa. Em função da metodologia utilizada nessa investigação e se seu objetivo, não pudemos aqui apontar as ferramentas e/ou os recursos utilizados pelos autores dos estudos componentes do corpus de análise para o monitoramento da qualidade da educação; ou ainda elementos/índices políticos e econômicos para a compreensão do que seriam as desigualdades.

Não podemos deixar de considerar ainda que a compreensão dos fenômenos articulados, demandaria uma aprofundamento teórico bastante profundo em cada um dos estudos que compõem o corpus de análise presente no presente artigo, o que nesse momento não era viável, entendo o objetivo deste estudo a partir de uma aproximação com os debates e discussões sobre essas temáticas a partir do que é produzido em teses e dissertações brasileiras, independente da origem (Programas de Pós-Graduação), no sentido de apresentar um panorama dos títulos correntes entre 2007 a 2017. Compreendemos que esse seja o próximo passo no desenvolvimento dessa investigação, já que a polissemia dos termos, acaba trazendo um conjunto de 
questões que servem como base (e em alguns casos, referenciais) para a implementação de políticas educacionais; articulação e desenvolvimento de ações; e documentos, recomendações e parâmetros legais.

Se observarmos a distribuição do conjunto de produções acadêmicas que formam o corpus de análise (Gráfico 01), percebemos que a produção de conhecimentos frente as temáticas da qualidade da educação superior e desigualdades se mostram a partir do desenvolvimento de estudos no nível do mestrado (um total de 36 produções, cerca de $70 \%$ de toda a produção presente no levantamento), majoritariamente, com a produção de dissertações. O quantitativo desta produção emerge de forma significativa em 2011, entre os anos de 2007 e 2010, essa produção se mostra bastante incipiente. A partir de 2011, temos o aumento crescente destas investigações até o ano de 2013, seguido de um leve decréscimo em 2014, uma retomada do crescimento em 2015, uma depressão expressiva em 2016 e uma retomada de mesmas proporções em 2017, evidenciando dessa forma um forte interesse pela comunidade de pesquisa em estudos sobre esses temas, especialmente em dissertações.

Um outro elemento de destaque que o estudo evidenciou é a composição do corpus de análise a partir dos distintos campos de saber, no interesse em compreender os fenômenos da qualidade da educação superior e das desigualdades a partir de perspectivas distintas as utilizadas tradicionalmente no campo de estudos da Educação. A Educação concentra $26,9 \%$ de toda a produção acadêmica, mais de um quarto, seguido das Ciências Sociais (13,5\%) e das Políticas Públicas (11,5\%). Nesse sentido, nos parece coerente, já que as questões de desigualdade e qualidade da educação, acabam muitas vezes ficando atreladas a estas 3 (três) dimensões, porém, nos chama a atenção a área das Ciências Sociais Aplicadas, a partir da Comunicação (1,9\%) e da Administração (3,85\%), buscarem articulações que possibilitem o entendimento de fenômenos relacionamos com as temáticas.

As temáticas investigadas acabam por compor um verdadeiro mosaico da distribuição da produção acadêmica no período de 2007 a 2017, particularmente a partir das categorias de análise que emergiram no aprofundamento desta construção. No cenário no qual desenvolvemos este estudo, a qualidade da educação superior e as desigualdades se apresentam a partir de distintos contextos: Políticas Públicas, 
Educacionais e Institucionais. Majoritariamente os estudos que compõem o corpus de análise se alinham ao debate das temáticas frente aos Contextos Institucionais, onde as questões ligadas a Avaliação e Garantia de Qualidade e a Gestão Institucional se consubstanciam. Temos também a relação das temáticas de estudo com as Políticas Públicas para a Educação Superior e sua articulação com Programas e Ações das distintas instituições de Ensino Superior, além do Políticas Públicas no espaço universitário. Se pensarmos ainda em um Contexto Educacional, a articulação das temáticas se desdobra em estudos que privilegiam a diversidade dos sujeitos que se inserem no Sistema de Educação Superior brasileiro, e a utilização dos indicadores de qualidade subsidiando processos decisórios no interior das instituições.

Ambas as temáticas de estudo, emergiram no contexto brasileiro em momentos distintos, e a partir do início do século XXI, essas discussões tornaram-se pungentes no campo acadêmico, para além da produção de conhecimento teóricos, já que essas realidades começaram a ser experienciadas no interior das instituições. A qualidade da educação superior, por exemplo, foi tomando corpo (como constructo) para além de dados quantitativos de avaliação a partir dos anos 90, com a emergência da qualidade social a educação superior, em oposição ao conceito de qualidade total trazido do mercado; os estudos sobre desigualdade recebe uma conotação plural a partir dos anos 90 igualmente, sendo que o reflexo dessa pluralidade larga mão de estritamente dados quantitativos (casos particulares em nível micro), censitários e começa a incorporar em si as questões socioeconômicas, raça e gênero majoritariamente, que sim - utilizaram esses dados estatísticos para explicar o fenômeno da desigualdade, mas também passaram a utilizar outras perspectivas de pesquisa para o entendimento do fenômeno (pesquisa qualitativa).

A complexidade dos fenômenos da qualidade da educação superior e as desigualdades é perpassada por uma série de variáveis para o seu entendimento, variáveis estas que não se consubstanciam em um estudo do tipo "Estado do Conhecimento" com foco no desenho de um panorama de produções acadêmicas situadas em um tempo (2007 - 2017) e em um espaço específicos (Teses e Dissertações de Programas de Pós-Graduação brasileiros). Porém, identificar esses movimentos de pesquisa; as comunidades que operam na busca pelo entendimento dos fenômenos; e seus focos de investigação, possibilitam uma primeira leitura sobre esse campo de 
estudos articulado (qualidade da educação superior e desigualdades) e possíveis lócus de produção desses conhecimentos. Os dados levantados a partir da metodologia de produção de Estados do Conhecimento, podem ser desdobrados em tantos outros casos seja desejo do pesquisador, isso faz com que o corpus de análise traduza um momento da história das comunidades de pesquisa, que pode ser contado de diferentes formas, sobre infinitas perspectivas teóricas e epistemológicas.

\section{Referências}

ARANHA, M. L. A. História da educação. São Paulo: Moderna, 1996.

BIANCHETTI, R. G. Modelo neoliberal e políticas educacionais. 3. ed. São Paulo: Cortez, 2001.

CAVALCANTE, J. F. Educação superior: conceitos, definições e classificações. Brasília, DF: INEP, 2000. Disponível em: http://bit.ly/2WLU5VD. Acesso em: 12 jun. 2019.

DALLA-CORTE, M. G.; SARTURI, R. C. Políticas públicas para a formação de professores e contextos emergentes na educação superior. Revista Internacional De Educação Superior, Campinas, v. 1, n. 2, p. 160-181, out./dez. 2015.

DIAS SOBRINHO, J.; RISTOFF, D. I. (org.). Avaliação democrática: para uma universidade cidadã. Florianópolis: Insular, 2002.

FERREIRA, N. S. de. A. As pesquisas denominadas "Estado da Arte". Educação \& Sociedade, ano 23, n. 79, ago. 2002. Disponível em: http://bit.ly/2IPShkE. Acesso em: 10 jun. 2019.

FIORENTINI, D.; LORENZATO, S. Investigação em educação matemática: percursos teóricos e metodológicos. 2 ed. Campinas: Autores Associados, 2007.

FONTOURA, J. S. D. de. Á.; MOROSINI, M. C. A gestão da educação superior no contexto da educação, profissional e tecnológica: os diferentes focos na pesquisa.

Revista Brasileira da Educação Profissional e Tecnológica, Natal, v. 2, n. 13, p. 137149, 2017. Disponível em: http://bit.ly/2KWwb2p. Acesso em: 15 jun. 2019.

FONTOURA, J. S. D. de. Á. A gestão da educação superior em contextos emergentes: a perspectiva dos coordenadores dos Cursos Superiores de Tecnologia do IFRS, Campus Porto Alegre. 204 f. Dissertação (Mestrado em Educação) - Universidade Católica do Rio Grande do Sul, Porto Alegre, 2018. Disponível em:

http://bit.ly/2wYetnb. Acesso em: 12 jun. 2019. 
LIMA, D. C. B. P.; FARIA, J. G.; TOSCHI, M. S. A produção do conhecimento na sociedade da informação: reflexões filosóficas sobre a pesquisa em educação. Educação e Filosofia Uberlândia, v. 28, n. 55, p. 373-393, jan./jun. 2014.

MARTINS, C. O que é política educacional?. São Paulo: Brasiliense, 1993.

MAUÉS, O. C.; BASTOS, R. dos. S. As políticas de educação superior na esteira dos organismos internacionais. Revista Brasileira de Política e Administração da Educação, v. 32, n. 3, p. 699-717, set./dez. 2016.

MELO, M. V. Três décadas de pesquisa em educação matemática na Unicamp: um estudo histórico a partir de teses e dissertações. 230 f. Dissertação (Mestrado em Educação) -Universidade Estadual de Campinas, Campinas, 2006. Disponível em: http://bit.ly/2Xi8Xuh. Acesso em: 15 jun. 2019.

MINAYO, M. C. S. (org.). Pesquisa social: teoria, método e criatividade. 17. ed. Petrópolis: Vozes, 2000.

MOROSINI, M. C. Estado de conhecimento e questões do campo científico. Educação, v. 40, n. 1, p. 101-116, 2015. Disponível em:

https://periodicos.ufsm.br/reveducacao/article/view/15822. Acesso em: 15 jun. 2019.

MOROSINI, M. C.; FERNANDES, C. Estado do conhecimento: conceitos, finalidades e interlocuções. Revista Educação Por Escrito, v. 5, n. 2, p. 154-164, 2014. Disponível em: http://bit.ly/2RubQ65. Acesso em: 12 jun. 2019.

OLIVEIRA, M. F. de.; MARTINELLI, D. P. Desenvolvimento Local e Arranjos Produtivos Locais: uma revisão sistemática da literatura. Interações (Campo Grande), Campo Grande, v. 15, n. 1, p. 47-58, jun. 2014.

RISTOFF, D. O novo perfil do campus brasileiro: uma análise do perfil socioeconômico do estudante de graduação. Revista Avaliação, v. 19, n. 3, p. 723-747, nov. 2014. Disponível em: http://bit.ly/2MU7Qx0. Acesso em: 11 jun. 2019.

SGUISSARDI, V. (org.). Educação superior: velhos e novos desafios. São Paulo: Xamã, 2000.

SVARTMAN, B. P.; CROCHIK, J. L.; MASSOLA, G, M. Breves comentários sobre o processo de democratização das universidades públicas. Psicologia USP, v. 27, n. 2, pp. 161-164, 2016.

Enviado em: $29 / 03 / 2019$ Aprovado em: 28/12/2020 